\title{
ESCOLA E VIOLÊNCIA: A BUSCA POR UMA AMPLIAÇÃO DO TERMO VIOLÊNCIA ESCOLAR FRENTE A REALIDADE BRASILEIRA
}

\section{SCHOOL AND VIOLENCE: THE SEARCH FOR AN EXTENSION OF THE TERM SCHOOL VIOLENCE AGAINST BRAZILIAN REALITY}

MARINO, Leonardo Freire ${ }^{1}$

\section{RESUMO}

Este texto propõe estabelecer algumas indagações a respeito da chamada violência escolar. Nele focalizamos alguns pontos que consideramos relevantes para o entendimento do conceito de violência escolar, seus aspectos constituintes, suas manifestações cotidianas e suas motivações. Para tanto, não estabeleceremos uma análise quantitativa ou que procure uma explicação fatalista deste processo. Nossa motivação não reside em entender as razões individuais da violência nas escolas, mas, perceber os fatores sistêmicos e simbólicos que tem interferido no atual processo de multiplicação dos casos de violência nas escolas brasileiras.

PalaVras-Chave: Violência, Violência Escolar, Sociabilidades Violentas, Juventudes.

\begin{abstract}
This text proposes to establish some questions about the so-called school violence. Here we focus on some points that we consider relevant for the understanding of the concept of school violence, its constituent aspects, its daily manifestations and its motivations. To do so, we will not establish a quantitative analysis or look for a fatalistic explanation of this process. Our motivation is not to understand the individual reasons of violence in schools, but to understand the systemic and symbolic factors that have interfered in the current process of multiplication of the cases of violence in Brazilian schools.
\end{abstract}

KeYwordS: Violence, School Violence, Violent Sociabilities, Youth.

\section{INTRODUÇÃO}

Penso que não é possível apreender em uma teoria o panorama completo do mundo contemporâneo e que, sobretudo, não é possível fixar em uma teoria seu movimento: temos de explorá-lo e conhecêlo, episódio por episódio, faceta por faceta. Nosso juízo e nossa imaginação se sentirão sempre atrasados em relação a totalidade do

\footnotetext{
1 Doutor em Geografia pela Universidade Federal Fluminense (UFF). Professor Adjunto da Universidade do Estado do Rio de Janeiro (UERJ). Docente do Programa de Pós-graduação em Ensino de Educação Básica. Universidade do Estado do Rio de Janeiro (UERJ). Rio de Janeiro, RJ, Brasil. e-mail: leofmarino@gmail.com
} 
fenômeno. Por conseguinte, o melhor método para explicar e traduzir nosso tempo e, talvez, um método um pouco jornalístico e um pouco cinematográfico.

MARIÁTEQUI, José Carlos. 2005. p.30.

Vivemos um período de grandes questionamentos das estruturas e normas escolares vigentes e, por conseguinte, de transformações no sistema educacional. Dentre estes desafios, merece destaque, a cada vez mais preocupante, necessidade de lidar com casos de agressões físicas e psicológicas, casos de assédios e de violência sexual, depredações e atos de vandalismos ${ }^{2}$. Neste cenário, independentemente das práticas de mediação adotadas ou da capacidade de resoluções de conflitos estabelecidas, são observados, cotidianamente, um número cada vez maior de conflitos e episódios classificados como violentos no interior das instituições de ensino.

Em um breve levantamento no site de pesquisas Google, com a expressão violência escolar, foram relacionados mais de 24 mil resultados ${ }^{3}$. Entre eles, merecem destaque uma grande variedade de artigos e análises, além de diferentes reportagens. Tal fato, indica uma grande preocupação no meio acadêmico com as manifestações da violência que ocorrem no ambiente escolar e sugerem a existência de uma realidade marcadamente violenta. Como exemplo da expressão que a violência tem atingido no interior das escolas, foram selecionados trechos de algumas reportagens publicadas em diferentes veículos de comunicação nos últimos anos:

MEC TEM MEDIDAS PARA ENFRENTAR AÇÕES DE VIOLÊNCIA NAS ESCOLAS - A preocupação com o fenômeno fez com que o termo bullying fosse incluído também na Pesquisa Nacional da Saúde do Escolar (PeNSE) de 2015.

Em fato mais recente de violência em ambiente escolar, no dia 13 de março de 2019, na Escola Estadual Professor Raul Brasil, no município de Suzano, no estado de São Paulo, a dupla de atiradores Guilherme Taucci Monteiro e Luiz Henrique de Castro, ambos ex-alunos, mataram cinco estudantes e duas funcionárias da escola. O bullying e a violência nas escolas tornaram-se grandes problemas, que pais, educadores, governos e toda a sociedade precisam enfrentar (Jornal Correio, 08 de abril de 2019).

\footnotetext{
2 De acordo com estudo da OCDE (Organização pela Cooperação e Desenvolvimento Econômico), o fenômeno da violência escolar não se restringe ao Brasil ou a realidade das grandes cidades brasileiras. De acordo com pesquisa realizada por esta instituição, $60 \%$ dos professores brasileiros relatam que convivem com situações de violência em salas de aula.

${ }^{3}$ Esta pesquisa foi realizada no dia 06 de abril de 2019.
} 
LÍDER NA AGRESSÃO DE PROFESSORES, BRASIL CONVIVE COM VIOLENNCIA NAS ESCOLAS - Especialistas defendem políticas públicas para enfrentar problema; solução, porém, não passa por armamento

Indicadores globais mais recentes colocam o Brasil como o país mais violento contra professores. Apenas no Estado de São Paulo, o número de docentes que disseram ser vítimas de algum tipo de violência cresceu nos últimos anos. De acordo com a pesquisa mais recente realizada pela Organização para a Cooperação e Desenvolvimento Econômico (OCDE), em 2013, 12,5\% dos professores ouvidos no Brasil disseram ser vítimas de agressões verbais ou de intimidação de alunos pelo menos uma vez por semana (Revista Veja, 13 de março de 2019).

BRASIL É 10 NO RANKING DA VIOLÊNCIA CONTRA PROFESSORES - CaSO de professora em Santa Catarina reabriu debate sobre agressões em sala de aula. Dados mais recentes da OCDE colocam Brasil com pior índice no mundo.

O soco desferido por um aluno contra o rosto de Marcia Friggi reabriu o debate sobre a violência contra os professores em sala de aula. Entretanto, o retrato da violência contra os docentes deixa o Brasil fora de foco. Os dados globais mais recentes colocam o país como o mais violento contra esses profissionais. Além disso, estudiosos do tema apontam que faltam levantamentos internos que promovam o diagnóstico do problema (Portal G1, 22 de agosto de 2017).

A VIOLÊNCIA QUE VAI À ESCOLA TODO DIA - Onde estão os responsáveis por alunos tão jovens, antes, durante e depois de eles passarem por traumas? O que fizeram para prevenir ou resolver o problema?

Quem vai a campo conhecer a realidade das escolas brasileiras ouve relatos tão assustadores quanto revoltantes. Crianças e adolescentes revelam experiências de assédio moral e sexual, agressão verbal e física, dramas psicológicos variados. Mas a frequência e a reincidência dessas práticas causam mais que assombro e indignação. Despertam uma pergunta básica: por quê? (Jornal o Globo, 22 de outubro de 2017).

A constante exposição destas informaç̧ões nos veículos de comunicação tem exacerbado o debate, provocando a construção de diferentes opiniões e sentidos a respeito das manifestações da violência escolar. No entanto, tais apreciações, em muitos casos, carecem de uma fundamentação teórica que contemple a realidade brasileira. Neste cenário, buscamos responder duas questões: Do que estamos falando quando mencionamos o termo violência escolar? A realidade vivenciada no interior das escolas brasileiras é capaz de explicar o crescimento dos casos de violência? 
Diante de tais questionamentos, construímos este ensaio. Não pretendemos apontar respostas definitivas para essas duas questões. Pelo contrário, buscaremos elencar algumas possibilidades de análise, identificar aspectos que devem ser levados em consideração nos estudos que procurem explicar o crescimento da violência no interior das escolas brasileiras e, especialmente, apontar o que, de acordo com nossos estudos, deve ser entendido como violência escolar.

Para tanto, o texto encontra-se estruturado em três partes: A primeira, intitulada ' $O$ conceito de violência e suas manifestações', terá como objetivo traçar um recorte conceitual do termo violência, uma vez que entendemos como fundamental qualificarmos este termo para apresentarmos o que entendemos por violência escolar; A segunda parte, intitulada 'As manifestações sistêmicas e simbólicas da violência no ambiente escolar', apresentará nossa busca por explicar de que forma a violência se estabelece no interior das escolas brasileiras. A terceira e última parte, intitulada ' $O$ que o crescimento da violência no ambiente escolar revela?, tem como foco apontar algumas consequências do cenário atual, especialmente, no que diz respeito as implicações provocadas pelas leituras ultra simplificadoras da violência no interior das instituições educacionais brasileiras.

\section{O CONCEITO DE VIOLÊNCIA E SUAS MANIFESTAÇÕES}

O elevado número de notícias veiculadas nos meios de comunicação e as diversas pesquisas centradas na temática da violência indicam que vivemos um período de grandes tensões e conflitos. Neste contexto, as manifestações cotidianas da violência são tão numerosas e diversas que se torna um grande desafio considerá-las como um processo único. Utilizamos o termo violência para descrever acontecimentos que envolvem agressões físicas e psicológicas e, igualmente, empregamos o termo violência para caracterizar questões de depredações e vandalismos. Além disso, é comum que questões sociais consideradas inaceitáveis aos nossos olhos, como por exemplo, a pobreza extrema e a exploração da mão-de-obra em condições análogas à escravidão, sejam caracterizadas como violentas. Tal fato torna o conceito de violência extremamente abrangente, complexo e diversificado, englobando em sua conceituação diferentes perspectivas teóricas e analíticas.

Para Hannah Arendt, a violência carregaria um aspecto instrumental que se diferenciaria das manifestações da força, da autoridade e do poder ${ }^{4}$. Em sua obra, intitulada 'Sobre a Violência' (1994), a pensadora judia-alemã apontou que a violência não decorreria de manifestações naturais do poder. De acordo com suas formulações,

\footnotetext{
4 "Penso ser um triste reflexo do estado da ciência política que nossa terminologia não distinga entre palavras-chave tais como poder, vigor, força, autoridade e, por fim, violência - as quais se referem a fenômenos distintos e diferentes, e que dificilmente existiriam se assim não fosse". ARENDT, Hannah, 1994 , p. 36.
} 
DOI: $10.12957 / \mathrm{e}-\mathrm{mosaicos} .2019 .41998$

o poder seria inerente a qualquer comunidade política, resultando da capacidade dos indivíduos de agirem coletivamente por meio da construção de consensos, uma vez que o poder nunca é propriedade de um indivíduo e que ele pertence a um grupo e existe apenas enquanto o grupo conserva-se unido (ARENDT, 1994, p.36). Arendt acreditava que quando o poder se desintegra, quando a vida política reduz sua capacidade de fomentar consensos, surgiriam as manifestações de violência. Portanto, seria a debilidade do poder e, consequentemente, da construção de consensos, a responsável pela emergência da violência, não o contrário. Assim, a violência não afirma o poder, mas o corrói e o destrói.

Concordando com o pensamento de Hanna Arendt, especialmente, em relação a natureza instrumental da violência, acreditamos que ela emerge em situações em que o poder está sendo perdido (ARENDT, 1994, p.41). Assim, momentos marcados por grande conflitualidade e pela multiplicação de casos de violência, como vivenciamos em nossos dias, evidenciam o enfraquecimento do poder, ou seja, demonstram que a construção de consensos se encontra debilitada e que, por isso, a violência passou a ser utilizada como instrumento necessário para a imposição de um ordenamento desejado.

Slavoj Zizek (2014), mais recentemente, ampliou o debate em torno do conceito de violência. Para ele, existiriam três dimensões da violência. A primeira dimensão, envolveria a violência visível e identificável, nomeada por ele como violência subjetiva, ela emanaria de fatos episódicos, acontecimentos inerentes as individualidades. A segunda dimensão, abarcaria a chamada violência sistêmica, que consistiria em expressões veladas da violência, aquilo que não vemos objetivamente, mas, que sustenta a ordem vigente, o grau zero de violência subjetiva. A violência sistêmica envolveria as estruturas econômicas, políticas e sociais que determinariam uma normalidade obtida por meio da coerção e da imposição de ordenamentos sociais e espaciais. A terceira e última dimensão, diz respeito a chamada violência simbólica, considerada como a mais fundamental forma de violência, uma vez que pertence ao campo da linguagem e carrega um universo de significados, de sentidos e de procedimentos classificatórios dos indivíduos ${ }^{5}$.

Para o pensador esloveno, as manifestações da violência não podem ser resumidas a atos e episódios violentos. A violência vivenciada cotidianamente envolveria uma complexidade de fatores explicativos, entre eles fatores subjetivos, sistêmicos e simbólicos. Assim, para compreender acontecimentos violentos

\footnotetext{
5 "A questão é que as violências subjetiva e objetiva não podem ser percebidas do mesmo ponto de vista: a violência subjetiva é experimentada enquanto tal contra o pano de fundo de um grau zero de não violência. É percebida como uma perturbação do estado de coisas "normal" e pacífico. Contudo, a violência objetiva é precisamente aquela inerente a esse estado "normal" de coisas. A violência objetiva é uma violência invisível, uma vez que é precisamente ela que sustenta a normalidade do nível zero contra a qual percebemos algo como subjetivamente violento. Assim, a violência sistêmica é de certo modo algo como a célebre "matéria escura" da física, a contrapartida de uma violência subjetiva (demasiado) visível. Pode ser invisível, mas é preciso levá-la em consideração se quisermos elucidar o que parecerá de outra forma explosões "irracionais" de violência subjetiva" (ZIZEK, 2014, p. 17).
} 
DOI: $10.12957 / \mathrm{e}-$ mosaicos.2019.41998

precisaríamos ultrapassar as interpretações que se pautam em responsabilidades individuais. Em seu lugar devemos estabelecer análises capazes de revelar de que forma os fatores sistêmicos e simbólicos interferem nas escolhas individuais. Caso contrário, determinados atos violentos aparecerão apenas como opções irracionais, incompreensíveis e inexplicáveis.

Ao apontar a existência de um fator sistêmico da violência, Zizek (2014) chama atenção para a relação temporal e espacial dos atos violentos. Para ele, as características gerais que envolvem o emprego do conceito de violência variam no tempo e no espaço e acompanham padrões sociais e culturais determinados ${ }^{6}$. Este aspecto deve ser levado em consideração quando analisamos as manifestações da violência no interior das instituições de ensino. É preciso entender de que forma as mudanças sociais, suas permanências, resistências e conflitos afetam a realidade dessas instituições. Portanto, não podemos descolar a violência subjetiva, estabelecida em processos que alteram o estado de normalidade institucional, de seus aspectos estruturais e simbólicos; aspectos que garantem um sentido explicativo para acontecimentos que, muitas vezes, são vistos de forma isolada e de maneira irracional.

No que tange as mudanças sociais, diversos pensadores se debruçaram a respeito de seus aspectos atuais. Nesta multiplicidade de análises, emergem diferentes leituras e, especialmente, distintas formas de encarar os aspectos imanentes do vivido. Neste conjunto, as análises de Foucault (2008 e 1987), Deleuze (1992), Agamben (2004 e 2002) e Byung-Chul Han (2017) merecem destaque. Tais pensadores apresentam importantes leituras e singularidades analíticas. Porém, existe uma questão comum nestas obras, os apontamentos a respeito da crise do modelo social vigente e, consequentemente, a transição para um novo modelo social.

Amparados por estas análises, podemos afirmar que vivemos um período de transição entre maneiras de ser e estar no mundo. Frente a tais acontecimentos, diversas instituições pretéritas, criadas pela chamada sociedade disciplinar, perderam importância e, mesmo que ainda sejam em algum grau necessárias, caminham para um amplo processo de reformulação ${ }^{7}$. A escola com suas regras, normas, punições, sansões e formas corriqueiras de exclusão, constitui uma das instituições que passam

\footnotetext{
${ }^{6}$ Este é o caso, por exemplo, das relações de casamento das mulheres que, em determinadas sociedades, são submetidas a imposições que em outras sociedades são consideradas como inadequadas.

7 "A escola, como concebida, representa uma instituição alicerçada em um modo peculiar de ser e estar no mundo, uma instituição que se ocupou em conformar os indivíduos aos padrões de conduta e as normas socialmente estabelecidas. Porém, em nossos dias, a escola perdeu parte de sua funcionalidade, sofrendo críticas constantes e fortes contestações sobre sua eficiência. Tal crítica se alicerça em profundas mudanças sociais. Vivenciamos uma transição entre modos de ser e estar no mundo, entre modos de vida que eram mais compatíveis com o modelo escolar tradicional, que se adaptavam mais facilmente as diversas tecnologias disciplinares, e modos de vida que não se adequam mais a um ambiente de confinamento, que carregam imensas dificuldades para se encaixarem nas moldagens disciplinares, que manifestam uma fragrante desconformidade com as instituições escolares" (MARINO, 2018, pp. 159-160).
} 
DOI: $10.12957 / \mathrm{e}-$ mosaicos.2019.41998

a sofrer profundos questionamentos. Sua autoridade moral, seu reconhecimento social e sua relevância laboral não são mais as mesmas que eram no passado. Com base nesta nova realidade, vivenciada, simultaneamente, por alunos, professores e demais profissionais de educação, ocorre a erosão de muitos consensos institucionais e a violência eclode como consequência dessa debilidade. No entanto, como apontado por Zizek (2014) não podemos resumir a violência ao ato violento. Devemos buscar de que forma a violência sistêmica e simbólica interferem nesta realidade.

Acreditamos que escola não constitui um ambiente descolado dos contextos sociais, pelo contrário, os acontecimentos sociais, econômicos e culturais são determinantes para as práticas, para a construção de saberes, para os procedimentos e para diversos acontecimentos que ocorrem no interior dessas instituições. Assim, diversos acontecimentos classificados como episódios de violência escolar, carregam uma complexidade que a racionalidade institucional não é capaz de explicar em sua totalidade. São acontecimentos que carregam uma explicação para além dos muros institucionais.

Neste sentido, a seguir, procuraremos elencar alguns fatores que consideramos como explicativos do aumento dos casos de violência escolar vivenciados no Brasil. Contudo, nesta análise, nos afastamos das leituras que procuram encarar a violência como inerente aos indivíduos maléficos e indisciplinados que habitam o interior de determinadas escolas. Assim, assumimos o desafio de estabelecer uma análise que procure elencar alguns aspectos sistêmicos e simbólicos que precedem ao ato violento. Portanto, não estaremos discutindo a violência escolar como um simples ato de indisciplina ou em uma perspectiva individual.

\section{AS MANIFESTAÇõES SISTÊMICAS E SIMBÓLICAS DA VIOLÊNCIA NO AMBIENTE ESCOLAR}

Em muitas escolas, o protagonista da violência é sempre o outro, especialmente, em relação aquele que não faz parte da 'comunidade escolar' ou que não se adequou a mesma e por isso foi apartado do convívio no seu interior. Neste processo, o tema da violência escolar é submetido a um tratamento que enfatiza a marginalidade daqueles que a cometem, submetendo a violência escolar a um discurso que individualiza 0 ato violento. Contudo, a complexidade que envolve a violência acarreta a necessidade de análises que integrem os fatores subjetivos, estruturais e simbólicos; análises em que as diversas dimensões da violência sejam consideradas e que não mascarem o fenômeno como um ato irracional determinado por escolhas individuais.

Ao estabelecer como motivação dos atos violentos a exterioridade; que a violência é produto daquele que não faz parte da comunidade, cria-se um discurso que procura mascarar a existência de um ambiente marcadamente violento. Um ambiente em que a alteridade dos indivíduos não é levada em consideração e que os consensos são buscados por meio de coerções; A forma homogeneizante de ensinar e aprender, a inexistência de espaços e momentos de escuta, o não reconhecimento das diferenças 
DOI: $10.12957 / \mathrm{e}-$ mosaicos.2019.41998

e a incapacidade de promover o protagonismo juvenil presente em diversas instituições educacionais, colaboram para a construção de ambientes assentados em práticas que não reconhecem o outro como sujeito, que não lhes confere um lugar de fala. A frustração com a impossibilidade de agir politicamente e de ter sua individualidade reconhecida, fomenta o uso da força como meio de reivindicação da própria voz. Por outro lado, a negação da fala e a necessidade de produzir um conjunto homogêneo de saberes, faz com que a violência seja encarada como um meio capaz de conformar alunos e professores as dinâmicas de ordenamento escolares e, consequentemente, sociais.

Frente a reduzida capacidade de produzir consensos, inúmeros alunos e professores entendem que a escola não constitui um espaço de pertencimento. A permanência no interior de seus muros passa a carecer de sentidos. Neste cenário, em muitos momentos, a violência se instala devido à incapacidade de reconhecimento de seus agentes constituintes. Ao não reconhecer o outro como fundamental, as relações de confiança e de consenso são enfraquecidas. Muitos conflitos estabelecidos no interior das escolas surgem como resultado da falta de consenso e diversas formas de coerção disciplinares originam-se na busca por restabelecer a autoridade institucional perdida. A violência surge, assim, da busca pela autoafirmação de um aparato corroído que perdeu a legitimidade necessária para fomentar consensos em seu interior ${ }^{8}$. Neste ponto, voltamos a Arendt (1994) e sua afirmação de que a violência é gerada pela incapacidade de um poder instituído de se afirmar como legitimo. Deste modo, uma das dimensões da violência escolar, nasceria de uma profunda crise vivenciada por este aparato, pelo enfraquecimento de sua autoridade institucional, aspectos, emanados da crise vivenciada pelo conjunto de instituições criadas pela sociedade disciplinar.

Não obstante as práticas de sujeição existentes no interior das escolas, é fundamental reconhecer que a realidade extramuros interfere, igualmente, na produção de conflitos e atos violentos na realidade intramuros. Todavia, não se trata de uma linearidade entre causa e efeito. Reconhecer que o que acontece no exterior das escolas interfere no seu interior expressa o reconhecimento de que não estamos tratando de estruturas hermeticamente fechadas, com muros intransponíveis, mas de espaços permeáveis e permanentemente vinculados aos contextos sociais e espaciais existentes.

Vivemos em uma sociedade marcada por profundas desigualdades, mas, igualmente, pela existência de um quadro elevado de conflitualidade e de violência. Neste processo, a violência socialmente instituída, emanada dos aparatos estatais e dos conflitos que envolvem grupos armados, se coaduna com uma histórica cultura da

\footnotetext{
8 "(..) com a administração especializada, despolitizada e socialmente objetiva e com a coordenação dos interesses como nível zero da política, a única maneira de introduzir paixão nesse campo e de mobilizar ativamente as pessoas é através do medo, um elemento constituinte fundamental da subjetividade de hoje. Por isso a biopolítica é em última instância uma política do medo que se centra na defesa contra o assédio ou a vitimização potenciais". ZIZEK, Slavoj 2014, p. 39.
} 
DOI: $10.12957 / \mathrm{e}-\mathrm{mosaicos} .2019 .41998$

violência e por práticas de controle alicerçadas no uso da força como normalidade ${ }^{9}$. 0 Estado brasileiro é incapaz de garantir o acesso as políticas sociais de maneira democrática para a população, este é o caso, por exemplo, das ações atreladas as políticas de segurança pública. Em um cenário caótico, parte das possibilidades de funcionamento regular de determinadas escolas e de implementação de suas atividades, dependem de negociações entre seus membros com grupos armados territorialmente estabelecidos ${ }^{10}$. Deste modo, a violência criminal penetra o muro da escola de forma efetiva, determinando, por exemplo, momentos de funcionamento e de fechamento.

Em paralelo a tais acontecimentos, a proximidade de uma realidade objetivamente violenta, contribui para a construção de expressões culturais que carregam as marcas da violência cotidiana. Em muitos momentos, a proximidade com atos bárbaros, como por exemplo, casos de assassinatos e de tortura, não despertam a atenção, o horror ou o espanto que deveriam provocar, sendo encarados de forma banal, corriqueira. Como um aspecto trágico dessa sociabilidade, os limites definidores do ato de destruição do outro, passam a ser inscritos em experiências cotidianas. A banalização da violência e a desvalorização da vida, presente no dia a dia de diversas comunidades, tem produzido uma sociabilidade assentada em práticas cada vez mais violentas. Consequentemente, a construção de sociabilidades violentas produz, ao mesmo tempo, sociabilidades violentas no interior das escolas.

O reconhecimento de que as contradições sociais brasileiras se manifestam no interior das instituições de ensino, isoladamente, não permite explicar a totalidade dos casos de violência. A violência é um fenômeno complexo, diverso e abrangente, cujas motivações não envolvem apenas um determinado aspecto, mesmo que este abarque características estruturais. Porém, o reconhecimento de um elevado grau de conflitualidade e a existência de sociabilidades marcadamente violentas servem para revelar a existência de dimensões sistêmicas e simbólicas que em análises episódicas, individualizantes, ficam invisíveis ou são desprezadas.

As instituições escolares vivem uma crise sem precedentes e a violência manifestada em seu interior revela apenas uma das facetas desta crise. Contudo, em que medida o crescimento dos casos de violência no ambiente escolar, utilizando uma expressão cunhada por Lefebvre (2008), não seria um elemento revelador de outras interfaces dessa crise, ou seja, a porta de acesso privilegiada para uma análise mais densa do próprio sentido de existência do sistema escolar, de suas contradições e de suas práticas atuais.

\footnotetext{
${ }^{9}$ Um exemplo deste processo residiria no mito da não-violência brasileira, um discurso que esconde uma sutil modalidade de violência apresentada como um pressuposto positivo de convívio social quando, de fato, este processo origina-se de formas de violência reais e objetivas destinadas a grupos sociais específicos.

${ }^{10}$ Um exemplo desta conflituosa relação envolve os relatos de fechamento de escolas e a suspensão de aulas em decorrência da morte de criminosos ou de momentos conflitos entre grupos rivais.
} 


\section{O QUE O CRESCIMENTO DA VIOLÊNCIA NO AMBIENTE ESCOLAR REVELA?}

De acordo com Foucault (2008 e 1987) e Deleuze (1992) as instituições escolares foram pensadas em um modelo social que buscava adequar os indivíduos aos interesses econômicos vigentes. Para eles, as escolas não foram estabelecidas como mecanismos de democratização do acesso à cultura ou ao conhecimento, mas, fundamentalmente, como espaços de disciplinarização dos indivíduos para o mercado, para a produção de corpos dóceis ${ }^{11}$. Com o passar do tempo, a escola ganhou outros significados, assumindo, especialmente, pelas camadas mais empobrecidas, o caráter de uma instituição capaz de promover a mobilidade social e econômica. No Brasil, o amplo movimento de expansão do ensino, iniciado na primeira metade do século XX, foi ao encontro desses anseios, especialmente, em relação aos estratos sociais mais empobrecidos, que almejavam obter meios efetivos de melhoria social. Deste modo, foi cunhada a ideia de que o caminho para o progresso material passaria pelos bancos escolares.

Atualmente, no entanto, as possibilidades reais de ascensão social e econômica pelo sistema de ensino público no Brasil são evidentemente mais reduzidas do que foram no passado. Estudos recentes evidenciam que o aumento dos níveis de escolaridade das camadas mais pauperizada não significa, automaticamente, uma melhoria de renda ${ }^{12}$. Se o conjunto de significados atribuídos ao papel da escola como instrumento de mobilidade social não está completamente esgotado, certamente, em algumas regiões, essa representação passa por um intenso processo de erosão. Este é o caso do que ocorre em muitas escolas localizadas em regiões periféricas. Em diversos agrupamentos sociais, sobretudo, nos mais empobrecidos, a rota traçada para a ascensão social e econômica não passa pela escola, mas fundamentalmente, pelo trabalho, mesmo que de forma informal.

Tal fato não significa que a escola perdeu sua capacidade de promover a ascensão social, pelo contrário, ela continua representando um dos poucos meios capazes de estabelecer este processo para os agrupamentos mais empobrecidos. No entanto, sua imagem como promotora de melhorias sociais e econômicas encontra-se deteriorada. Com base nesta imagem, muitos jovens passam a entender que, independentemente, de sua trajetória, não obterão os meios suficientes para ancorar o conjunto de expectativas depositadas no projeto escolar e, por isso, se sentem

\footnotetext{
11 "A disciplina fabrica assim corpos submissos e exercitados, corpos 'dóceis'. A disciplina aumenta as forças dos corpos (em termos econômicos de utilidade) e diminui essas mesmas forças (em termos políticos de obediência) [...] a coerção disciplinar estabelece no corpo o elo coercitivo entre uma aptidão aumentada e a dominação acentuada" (FOUCAULT, 1987, p. 127).

12 De acordo com a pesquisa da OCDE intitulada, seriam necessárias nove gerações para que os descendentes dos brasileiros situados entre os $10 \%$ mais pobres atingissem o nível de rendimento médio do país. De acordo com este levantamento, $35 \%$ dos filhos de pais posicionados nos $20 \%$ mais pobres terminam a vida nesse mesmo estrato social. Apenas $7 \%$ deles chegam a figurar entre os $20 \%$ mais ricos.
} 
DOI: $10.12957 / \mathrm{e}-\mathrm{mosaicos} .2019 .41998$

impelidos a abandonarem esta instituição. A escola não constitui para estes jovens um espaço significativo, um lugar em que desejariam estar. A escola não pertence ao conjunto de seus interesses pessoais.

Em paralelo a gradual erosão do projeto escolar como mecanismo de ascensão social, ocorre a progressiva deterioração da concepção da escola como instituição responsável pela reprodução de saberes tradicionais (ARROYO, 2001). A capacidade uniformizadora de saberes oriunda da tradição escolar, tem sido, cotidianamente, colocada à prova, abrindo espaço para um movimento que aprofunda a crise vivenciada pelo conjunto das instituições de ensino. As escolas não detêm mais a exclusividade pela transmissão do conhecimento, uma vez que em nossos dias o mesmo encontra-se espraiado pelo tecido social e disponível de forma descolada de muros institucionais ${ }^{13}$. Como consequência, muitos alunos e professores não entendem as razões de suas práticas, dos conteúdos que são discutidos e das metodologias que são empregadas.

Este cenário, aponta uma ambiguidade nas relações entre as juventudes e a escola, uma vez que ao mesmo tempo em que os jovens são determinados a frequentarem e permanecerem no seu interior, são confrontados, simultaneamente, por processos que levam a apartação, a intermitência e ao abandono. Muitos alunos estão na escola, frequentam esses espaços, porém, estão pouco permeáveis ou disponíveis a sua influência. Tal fato não deve ser encarado como inerente aos indivíduos pauperizados, perpassando todos os estratos sociais e sendo presenciados em diversas instituições. Todavia, quando este processo se relaciona com as juventudes periféricas, os desiguais socialmente passam a ser encarados como desiguais em rendimento. O que é denunciado por Arroyo (2010) ao afirmar que os desiguais em qualidade social, racial, cultural são destacados como os responsáveis pela desigual qualidade das escolas. Ao classificarmos os coletivos de alunos periféricos como incapazes, inocentamos o sistema, o Estado e suas instituições; inocentamos a história de produção das desigualdades e de violências estruturais e simbólicas ${ }^{14}$. As desigualdades escolares não podem ser reduzidas a capacidades desiguais dos alunos; não podemos responsabilizar as, principais, vítimas de uma violência sistêmica e simbólica pelas desigualdades dos rendimentos escolares.

\footnotetext{
13 "No mundo interconectado no qual vivemos, nossa relação com os saberes mudou. A internet e as conexões produzidas pelas redes sociais tornaram o acesso ao conhecimento muito mais democrático do que foi no passado. Guardada as devidas limitações provocadas pela desigualdade de acesso as novas redes e tecnologias, atualmente, cada indivíduo, dotado de um equipamento eletrônico, como por exemplo, um smartphone, sem realizar qualquer deslocamento físico, pode participar dos debates que inflamam nossa sociedade, conectar-se com fóruns de discussões que envolvem indivíduos de todo o globo terrestre e produzir conhecimentos e conteúdos variados; uma nova forma de espaço público nasceu e nele a praça física perdeu a função de espaço exclusivo de luta, passando a conviver harmoniosamente com a praça virtual" (MARINO, 2018, p. 163).

14 "Pesquisas vêm mostrando as conexões entre a violência infanto-juvenil e as violências de que crianças, adolescentes e jovens padecem. Entretanto, as indagações e as reações concentram-se mais na condição de réus e agentes infanto-juvenis de atos de violência do que na sua condição de pacientes e vítimas" (ARROYO, 2007, p. 789).
} 
Por essas razões, um dos principais desafios provocados pelo aumento da violência escolar, envolve a redefinição de suas funções. É preciso abandonar os modelos de avaliações tradicionais, centrados exclusivamente nos alunos e em seus coletivos, para avaliarmos, conjuntamente, as estruturas, os ordenamentos, as lógicas, seus rituais e seus valores reprodutores e legitimadores das desigualdades sociais, raciais, étnicas e de gênero. Os temas centrais contidos na ideia de democracia, a valorização dos espaços públicos, dos direitos, da tolerância e do respeito às diferenças constituem pré-condições para a construção de novas atribuições e de novos sentidos para a instituição escolar. Trata-se de propiciar possibilidades de outras convivências e de novos significados para uma instituição que carrega em seu interior as marcas do autoritarismo, da coerção, da violência e do desprezo pelas alteridades.

$\mathrm{Na}$ ausência de novas referências, a indiferença e a violência episódica serão respostas frequentes e banalizadas, expressões parciais de uma crise que atinge os sistemas escolares e que envolve toda a sociedade brasileira. A violência de depredações, agressões físicas e desrespeito às normas instituídas, representa apenas a expressão mais visível de recusa aos valores transmitidos por um artefato que, gradativamente, perde sua importância e autoridade social. Certamente existem outros fatores explicativos para as recentes manifestações individuais de violência no ambiente escolar. Contudo, é inegável que a violência manifestada no interior das escolas apresenta uma intrínseca complexidade que análises individualistas e fatalistas não conseguem atingir.

A redução da violência ao ato violento, obscurece as múltiplas facetas do mundo e não contribui para entendermos as origens da brutalidade. Não devemos isentar os fatores individuais, subjetivos, não devemos absolver incondicionalmente as pessoas que realizam atos violentos. Porém, é fundamental que investiguemos suas origens e trajetórias; é necessário entendermos o papel que a sociedade e o Estado, por meio dos aparatos escolares, desempenham na formação desses indivíduos e na concreção de uma conjuntura social cada vez mais violenta. Como nos alertou Poulantzas (2000), os problemas reais são bem graves e complexos para serem resolvidos por generalizações ultra simplificadoras e grandiloquentes, que jamais conseguiram explicar o que quer que seja.

\section{CONSIDERAÇõEs FinaIS}

A violência não provém apenas da negatividade, mas também da positividade, não apenas do outro ou do estranho, mas também do igual. (...) A violência da positividade não pressupõe nenhuma inimizade. Desenvolve-se precisamente numa sociedade permissiva e pacificada. Por isso ela é mais invisível que uma violência viral (HAN, 2017, p.15-19). 
Acreditamos que a escola caminha para a formação de ambientes em que os conteúdos tradicionais não ocupem mais a centralidade do fazer docente. A escola carrega as marcas de um potencial transformador, em seu interior, diariamente, crianças e jovens mantêm contato estruturado com adultos que não são membros de suas famílias. A partir desse contato, direto e/ou indireto, entre adultos, jovens e crianças muitas experiências são adquiridas, fato que transforma o ambiente escolar em um espaço singular de relacionamentos, um espaço que carrega um potencial de transformação social. No entanto, mesmo com o grande potencial transformador, diversas questões e dinâmicas relacionadas à vida humana têm encontrado eco nas paredes das escolas. A violência, representa apenas uma delas. São frequentes e intensos os relatos de membros da comunidade escolar de situações de violência presenciadas no interior e no entorno das unidades educacionais, agressões, depredações, tráfico de drogas e casos de violência sexual representam apenas alguns exemplos de um quadro extremamente diversificado e em franca espiral de crescimento.

Neste cenário, professores, alunos, diretores, coordenadores e responsáveis tornam-se reféns de uma dinâmica que em muito lhes ultrapassam, restando apenas um misto de resignação, desconforto e, inevitavelmente, desestímulo e desesperança. A violência tem feito muitas vítimas nas escolas e levado a um inevitável esvaziamento do ambiente escolar. O medo passa a fazer parte do dia a dia da escola e a evasão se torna uma constante, seja por parte de alunos, que abandonam os bancos escolares, seja por parte de profissionais da educação, que acuados optam por largar o magistério.

Em alguns casos, especialmente, naqueles em que a origem da violência é identificada em um ato ou atitude que pode ser encarada de forma individualizada, a solução encontrada resvala no isolamento, na apartação do transgressor do ambiente escolar. Solução que ao contrário de conceber uma resposta definitiva ao problema, apenas atua em uma dimensão da violência e reduz o potencial transformador que a educação pode provocar. A descrença na capacidade transformadora da educação contrasta com a visão de que a escola funciona como um espaço destinado a formação humana. Assim, se constrói uma visão de que a escola deve atender apenas aos indivíduos humanizáveis, o que leva a desumanização dos indivíduos mais vulneráveis aos processos violentos, classificados como indesejáveis, marginais, bárbaros e violentos.

Ao tratamos como réus, as vítimas de um sistema assentada em práticas violentas, não consideramos os aspectos sistêmicos e simbólicos que precedem a violência subjetiva e episódica. Assim, reforçamos uma concepção limitadora, simplista e individualizante da violência escolar. Concepção que não consegue explicar a complexidade inerente aos fenômenos violentos e que aliena parte de suas origens em leituras superficiais. Além disso, ao assentamos nossas soluções no afastamento dos 
DOI: $10.12957 / \mathrm{e}-\mathrm{mosaicos} .2019 .41998$

'bárbaros', silenciamos os indivíduos que são, simultaneamente, algozes e vítimas. Determinamos uma solução simplista que não contempla o potencial transformador dos processos educativos e das relações humanas.

\section{REFERÊNCIAS:}

AGAMBEN, Giorgio. Estado de Exceção. São Paulo: Boitempo, 2004.

Homo Sacer: o poder soberano e a vida nua I. Belo Horizonte: Editora UFMG, 2002.

ARENDT, Hannah. Sobre a Violência. Rio de Janeiro: Relume Dumará, 1994.

ARROYO, Miguel. Políticas Educacionais e Desigualdades: à procura de novos significados. In.: Educação e Sociedade. Campinas. Unicamp, v. 31, n. 113, outubrodezembro. 2010. pp 1381-1416.

Quando a violência infanto-juvenil indaga a pedagogia. In.: Educação e Sociedade. Campinas. Unicamp, v. 28, n. 100, outubro-dezembro. 2007. pp. 787807.

A educação de jovens e adultos em tempos de exclusão. In.: Alfabetização e Cidadania, São Paulo: RAAB, n.11, abr. 2001. pp.9-20.

DELEUZE, Gilles. Conversações. Rio de Janeiro: Editora 34, 1992.

DOWDNEY, Luke. Crianças do tráfico: um estudo de caso de crianças em violência armada organizada no Rio de Janeiro. Rio de Janeiro: 7 Letras, 2003.

HAN, Byung-Chul. Sociedade do Cansaço. Rio de Janeiro: Editora Vozes, 2017.

FOUCAULT, Michel. Segurança, Território e População: curso no Collège de France (1977-1978). São Paulo: Martins Fontes, 2008.

Vigiar e punir: história da violência nas prisões. Petrópolis: Vozes, 1987.

LEFEBVRE, Henri. Espaço e Política. Belo Horizonte: Editora UFMG, 2008.

MARIÁTEQUI, José Carlos. Do sonho às coisas. São Paulo: Boitempo, 2005.

MARINO, Leonardo Freire. Derrubando Muros e Cercas: novas abordagens para o ensino de Geografia no século XXI. In.: Revista e-Mosaicos, Universidade do Estado do Rio de Janeiro. V.7, n 15, 2018. 
DOI: $10.12957 / \mathrm{e}-\mathrm{mosaicos} .2019 .41998$

- Geografia e poder: o ordenamento territorial da cidade do Rio de Janeiro e a genealogia da violência policial no Brasil. In.: Revista Biblio $3 w$, Universidade de Barcelona, outubro de 2017.

Focamos no Diabo e esquecemos do Inferno. Justificando - Revista Carta Capital. São Paulo. 7 de março de 2017. Disponível em: <http://justificando.cartacapital.com.br/2017/03/07/focamos-no-diabo-eesquecemos-doinferno/>

OCDE - Organização para a Cooperação e Desenvolvimento Econômico. Um olhar sobre a educação (Education at a Glance 2018). Disponível em:

$<$ http://portalods.com.br/publicacoes/education-at-a-glance-2018-um-olhar-sobre-aeducacao/>

POULANTZAS, Nicos. O Estado, o poder, o socialismo. São Paulo: Paz e Terra, 2000.

SIBILIA, Paula. Redes ou paredes: a escola em tempos de dispersão. Rio de Janeiro: Contraponto. 2012.

ZIZEK, Slavoj. Violência. São Paulo: Boitempo, 2014.

Recebido em 16 de abril de 2019

Aceito em 14 de julho de 2019 Licença Creative Commons - Atribuição-NãoComercial 4.0 Internacional.

Os direitos autorais de todos os trabalhos publicados na revista pertencem ao(s) seu(s) autor(es) e coautor(es), com o direito de primeira publicação cedido à e-Mosaicos.

Os artigos publicados são de acesso público, de uso gratuito, com atribuição de autoria obrigatória, para aplicações de finalidade educacional e não-comercial, de acordo com o modelo de licenciamento Creative Commons adotado pela revista. 